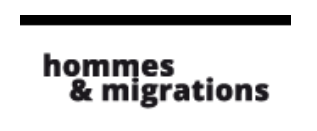

\section{Hommes \& migrations}

Revue française de référence sur les dynamiques

migratoires

$1324 \mid 2019$

Religion et discrimination

\title{
Ta-Nehisi Coates, Huit ans au pouvoir. Une tragédie américaine
}

Traduit de l'anglais (États-Unis) par Diana Hochraich, Paris, Présence africaine, 2018, 308 p., 24,90€

\section{Moustapha Harzoune}

\section{(2) OpenEdition}

\section{Édition électronique}

URL : https://journals.openedition.org/hommesmigrations/8743

DOI : 10.4000/hommesmigrations.8743

ISSN : 2262-3353

\section{Éditeur}

Musée national de l'histoire de l'immigration

\section{Édition imprimée}

Date de publication : 1 janvier 2019

Pagination : 226-227

ISBN : 978-2-919040-44-5

ISSN : 1142-852X

Référence électronique

Moustapha Harzoune, "Ta-Nehisi Coates, Huit ans au pouvoir. Une tragédie américaine », Hommes \& migrations [En ligne], 1324 | 2019, mis en ligne le 01 janvier 2019, consulté le 06 janvier 2022. URL : http://journals.openedition.org/hommesmigrations/8743; DOI : https://doi.org/10.4000/ hommesmigrations.8743 


\section{Huit ans au pouvoir. Une tragédie américaine}

Ta-Nehisi Coates. Traduit de l'anglais (États-Unis) par Diana Hochraich, Paris, Présence africaine, 2018, 308 pages, 24,90 euros.

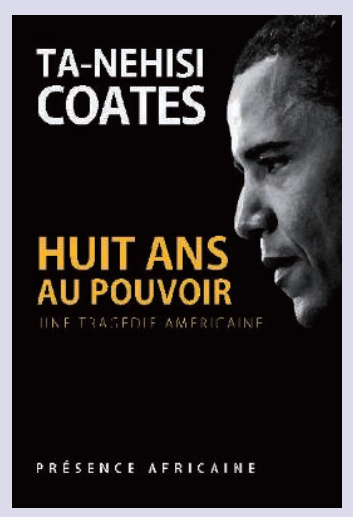

Quel livre! Ou plutôt quels articles! Car Coates est journaliste et cette publication rassemble huit papiers écrits tout au long de la présidence Obama pour le site d'information The Atlantic. Huit papiers remis chacun en perspective par une introduction rédigée ex post, où l'auteur donne les conditions de leur écriture, les discute, les commente, les critique même. Si l'auteur se raconte, ce n'est pas par nombrilisme. Lorsque Coates revient sur son enfance, sur sa famille, sa mère enseignante, son père membre des Black Panthers, ses années d'école, son mariage, ses doutes et ses réussites, le hip-hop, sa vie d'Afro-Américain né en 1975 du côté de Baltimore, ou lorsqu'il évoque la mort de son ami Prince Jones abattu en 2000 par un policier..., c'est pour dire et montrer les soubassements, les ressorts de sa pensée, ses grilles de lecture. Ce n'est pas pour faire le kéké que Coates parle de lui, mais, semble-til, par honnêteté intellectuelle. L'infiniment petit n'est pas repli narcissique mais volonté de traduire l'infiniment grand. Ou quand l'expérience individuelle rejoint l'expérience collective.
Ce qui frappe à la lecture de ces longs papiers, c'est le talent de l'auteur: brio des reportages (Chicago, Obamacare, incarcération des Noirs...) et des portraits (Michelle ou Barack Obama, Bill Cosby ou des anonymes); hauteur de vue des réflexions; densité des raisonnements structurés autour de récits d'expérience et de témoignages, de références et de sources multiples, universitaires, statistiques, et surtout historiques. Car le tragique ici s'enracine dans l'histoire du pays, dans le pillage des Noirs, depuis l'esclavage jusqu'aux subprimes, en passant par l'exploitation salariale, les lois Jim Crow, les détentions massives. Pour Coates, l'existence et la prospérité des États-Unis ont pour fondement la violence faite aux Noirs. Au pays dit de la liberté, "c'est l'esclavage qui a permis la démocratie».

L'élection d'Obama, ses discussions avec le président ont pu faire vaciller le pessimisme et la « défiance» de Ta-Nehisi Coates. L'intelligence du président, sa confiance en l'Amérique auraient pu emporter les doutes. C'était compter sans la rigueur des analyses du journaliste. Sans son expérience. West Baltimore n'est pas Hawaï. Avoir des grands-parents blancs aimants n'a rien de commun avec une enfance passée dans "un monde à part», où jamais il ne croisa de Blancs. Obama et Coates, ce sont deux regards différents, deux histoires américaines.

National Book Award pour Between the World and Me (Une colère noire, Autrement, 2016), Ta-Nehisi Coates appartient à cette génération d'intellectuels afroaméricains plus proches de Baldwin ou de Malcom X que de Martin Luther King. Pour lui, la question raciale, entendre la suprématie blanche, est et reste, même après la victoire d'Obama, au cœur de l'histoire américaine. Surtout après: l'élection de Trump en est la parfaite illustration.

En 1835, Gustave de Beaumont écrivait, dans Marie ou l'esclavage 
aux États-Unis, que «dans ces États de prétendue liberté, le nègre n'est plus l'esclave; mais il n'a de l'homme libre que le nom». Pour l'observateur français, l'horizon des États-Unis était tout entier contenu dans cette "grande plaie de la société américaine». Lire les articles de Coates, crayon à la main, c'est s'inspirer d'une méthode, d'une exigence intellectuelle, pour dire le tragique d'un monde sans rien céder à la haine, à la démagogie ou au misérabilisme.

M. H.

Avec cet ouvrage, fruit de son travail dans le cadre de l'École des hautes études en sciences sociales, Yves Tsao contribue à faire sortir de l'oubli un épisode important de la Première Guerre mondiale: la venue en France, à partir d'août 1916, de 37000 travailleurs chinois. S'inscrivant ainsi dans l'enjeu mémoriel posé par la commémoration du centenaire de laGrande Guerre, Yves Tsao s'en 